\title{
Performance Improvement of the Single-Phase Induction Motor by Using a Statically-Controlled Capacitor
}

\author{
M. M. Khater \\ Department of Electrical Engineering, Faculty of Engineering, \\ Menoufiya University, Shebin El-Kom
}

\begin{abstract}
This paper presents an approach for improving both the starting and running performance of the single-phase induction motor using a statically controlled capacitor. The control principle is based on a PWM switching for the auxiliary series capacitor using a pair of fast electronic switches. The proposed scheme ensures continuously varying capacitance of the auxiliary circuit. A d-q model for the single-phase induction motor operating under the proposed control has been developed and numerically analyzed. The optimum operating conditions for starting and running has been obtained. A laboratory set-up has been built and experimentally tested to examine the proposed control. Simulation and experimental results are compared and shown to be in good agreement.
\end{abstract}

\section{INTRODUCTION}

Single-phase induction motors are widely used specially in domestic and office applications. They have the advantages of rugged construction, maintenancefree and low cost. The main problem of this motor is that it is inherently of no starting torque. Starting is usually achieved by different means such as phase splitting or auxiliary winding with a capacitor. The starting method depends on the required starting torque for a specific application. Generally, split-phase motors are suitable for light-load starting, while capacitor motors are applicable for starting under full load.

In capacitor motors, the capacitor is connected in series with an auxiliary winding to realize another phase so that the motor can operate as a two-phase machine. For this purpose the capacitor size must be carefully determined according to the impedance of the auxiliary winding. This impedance changes widely from starting to running conditions. Hence, from the performance point of view, it is not practical to use only one fixed capacitance for both starting and running. If high starting torque and good running conditions are needed, at least two capacitors must be used with the auxiliary winding,

Manuscript received from Dir. M.M.Khater on : 25/10/1999

Accepted on : 24/11/1999

Engineering Research Bulletin, Vol 23,No 1, 2000 Minufiya University, Faculty of Engineering, Shebien El-Kom, Egypt, ISSN 1110-1180 
Capacitor-start capacitor-run motors use large capacitor during starting to ensure that the currents in the main and auxiliary windings are balanced, yielding a relatively high starting torque. This starting capacitor is usually switched-off just before the operating speed is reached and a small permanent capacitor is left. The permanent capacitance should be enough to balance the currents at normal motor loads and therefore, the motor operates efficiently with good power factor. This type of motors has two main drawbacks, it provides only two different capacitor values for the two operating conditions, and uses a mechanical switch which reduces the motor reliability. Improved motor performance requires the capacitance to be continuously varied with the operating condition.

Different techniques have been developed for controlling the current of the auxiliary winding of single-phase induction motors[1-5]. Two bi-directional electronic switches were used in Ref [1] to control the current of both main and auxiliary windings. This technique was applied to maximize the starting torque and to control the speed as well as the direction of rotation of a split-phase induction motor. A dc-charged capacitor switched by a transistor H-bridge has also been introduced [2,3]. In these references a PW/M switching technique was implemented using four bipolar transistors to control the auxiliary capacitance. This method of control appears to be effective but on the expense of using high number of switching devices and accordingly cornplicated gate drive circuits. Two back-to-back gate turn off (GTO) thyristors have been used for controlling the capacitor. [4,5]. Such a technique depends on short-circuiting the auxiliary capacitor for certain period of the half cycle. Besides the complexity arised with GTOs, the winding and input currents are too distorted which introduces a substantial amount of harmonics. In Ref [4] the switching control was implemented by a simple hardware, while in [5] the control process has been implemented by the TMS320 digital signal processor (DSP). The use of a DSP enables the user to deal with the system efficiently, however its high cost can not be justified for most applications. A different techuique has been used for controlling the value of the auxiliary capacitor for a single-phase reluctance motor [6]. In that reference a PWM switching scheme was applied to two bidirectional switches for continuous adjustment of the capacitor value. This technique was applied to enhance the synchronization process and to improve the motor stability.

In this paper an analysis has been carried-out to study the effect of varying the auxiliary capacitance of a single phase induction motor on its starting and running performance. A PWM switching scheme is proposed to control the effective value of the auxiliary winding capacitance. The work aims at replacing the two capacitors of the capacitor-start capacitor-run motor by a single controlled capacitor such that high starting torque and high running performance can be achieved. The system is mathematically simulated and experimentally verified. 


\section{SYSTEM DESCRIPTION}

Figure 1 shows the circuit diagram of the motor under consideration. The experimental motor is of $0.5 \mathrm{kw}, 220 \mathrm{~V}$, 4-pole with the parameters given in the appendix. Two IGBT switches $S_{1}$ and $S_{2}$ of type 250101 are used. Each transistor is fed through a fast recovery diode bridge in order to be able to conduct the auxiliary winding current in either direction. Hence, controlling both positive and negative half cycles of the auxiliary current is possible by the two switches $S_{1}$ and $S_{2}$. Gate signals for the two switches are such that there is no overlap between the two switches $S_{1}$ and $S_{2}$.

The auxilary circuit capacitance can be controlled by alternate switching of $S_{1}$ and $S_{2}$ of Fig.1. The motor operation alternates between two different modes. In Mode $1, S_{1}$ is turned-on such that $V_{a b}$ is zero while $S_{2}$ is turned-off such that $V_{c}$ is maintained constant. In Mode 2, $S_{1}$ is turned-off while $S_{2}$ is turned-on such that $V_{a b}$ equals the capacitor voltage $V_{c}$. Since the switching process is carried-out at a high frequency compared with that of the supply voltage, the two modes alternate many times per half cycle. By this switching process the auxilary capacitor is inserted, repeatedly, in series with the auxilary winding. The voltage across $S_{1}\left(V_{a b}\right)$ looks like PWM pulses superimposed on a sine wave with an effective value depending on the duty ratio $k$ of $S_{1}$. Its effective value increases with the decrease of that ratio and decreases with its increase. This voltage is effectively the voltage drop across the capacitor impedance, as it is seen by the auxilary winding. This means that the increase of the ratio $k$ has the effect of low effective capacitor impedance and accordingly a high effective capacitance and vice versa.

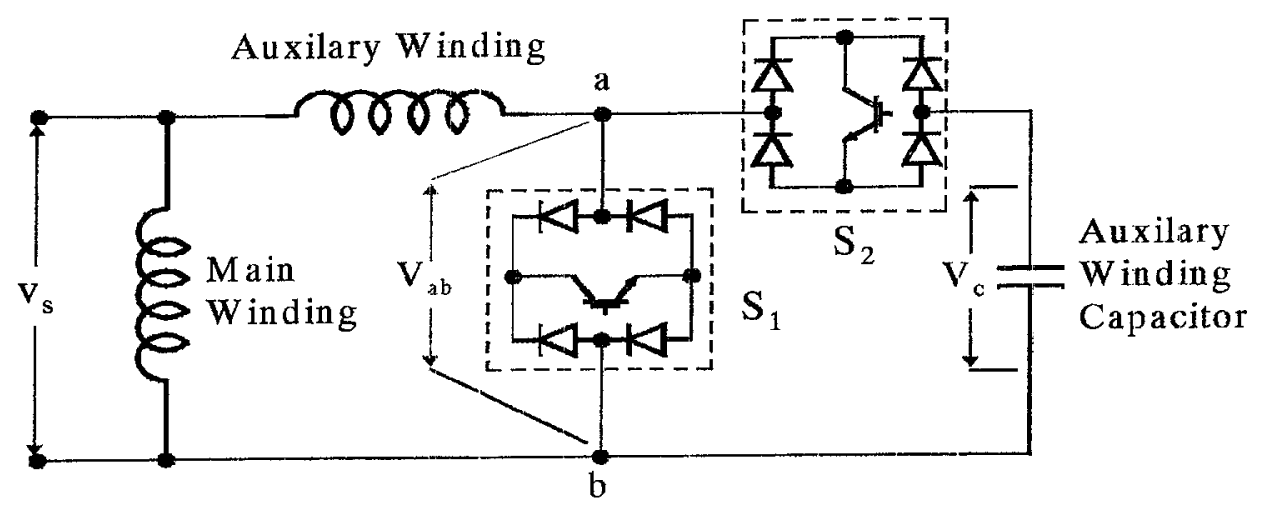

Fig. 1 The circuit diagram of the motor with the controlled capacitor.

The duty ratio $k$ determines the effective capacitance and accordingly, the auxiliary current required to achieve the desired motor operation. Figure 2, shows a schematic diagram for the closed-loop control of the capacitor. A dc signal $\omega_{\mathrm{r}}$ obtained from a tacho-generator to represent the motor speed is subtracted from a constant reference value $\omega_{\text {ref }}$. The error signal is multiplied by the gain of a proportional controller to get $\mathrm{V}_{\text {ref. }}$. This value is compared with a high frequency triangular carrier signal of $1 \mathrm{Khz}$ and the output is fed to the 
gate drive circuits through a NAND latch. The latch ensures that there is no overlap edges between the gate drive signals of both $S_{1}$ and $S_{2}$ to avoid shortcircuiting the charged capacitor. Each of $S_{1}$ and $S_{2}$ is switched-on and off ten times per half cycle of the supply frequency. This moderate switching frequency $(1 \mathrm{Khz})$ is chosen to compromise between the s'witching losses and smooth variation of the auxiliary winding current. The level of $V_{\text {ref }}$ controls the duty ratios of both $S_{1}$ and $S_{2}$. The two gating signals are distributed such that low speed obtains a large value for the ratio $k$. The proportional controller gain is chosen such that at rated speed the value of $V_{\text {ref }}$ almost equals the amplitude of the high frequency carrier signal. This choice has the effect that, at rated speed $S_{1}$ is almost off and $S_{2}$ is almost on. This means that the auxiliary capacitor is controlled during starting period and at any speed below the rated speed.

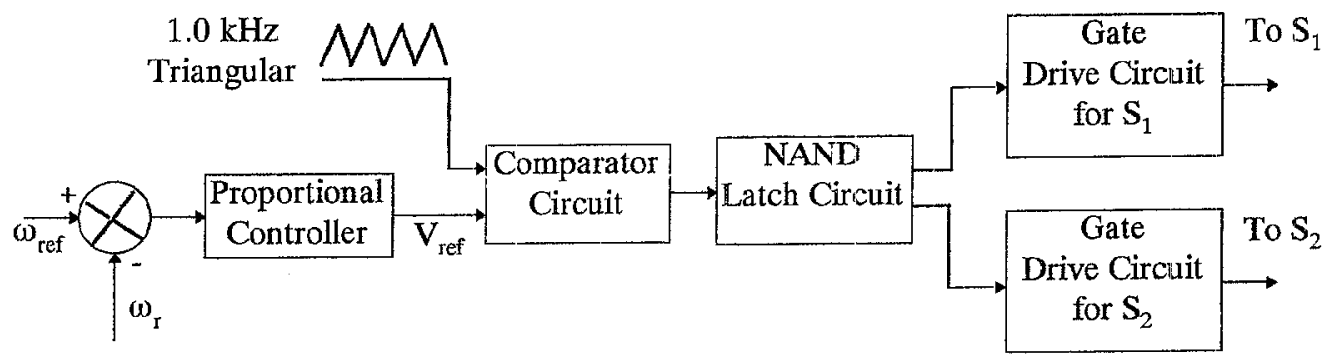

Fig. 2 A schematic diagram for the closed-loop control of the capacitor.

\section{MATHEMATICAL MODEL AND SIMULATION}

Since the main and auxiliary windings are already orthogonal, for simplicity in analysis, the stationary $\mathrm{dq}$ axes may be aligned with the orthogonal axes of the physical windings. The dq reference frame is chosen such that its q-axis is aligned with the axis of the main winding and its d-axis with that of the auxiliary winding as shown in Fig. 3.

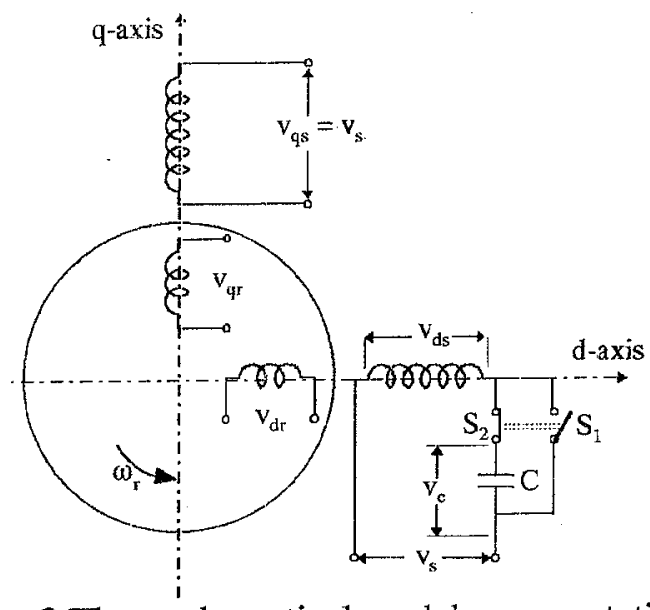

Fig. 3 The mathematical model representation.

(Switches S1 \& S2 are electronically interlocked) 
The voltage equations of the qs. and ds stator windings may be expressed in terms of the transformed and referred quantities as;

$$
\begin{aligned}
& v_{\mathrm{qs}}=i_{\mathrm{qs}} R_{\mathrm{qs}}+\rho \lambda_{\mathrm{qs}} \\
& \mathrm{v}_{\mathrm{ds}}^{\prime}=i_{\mathrm{ds}}^{\prime} R_{\mathrm{ds}}^{\prime}+\rho \lambda_{\mathrm{ds}}^{\prime} \\
& \mathrm{v}_{\mathrm{qr}}^{\prime}=i_{\mathrm{qr}}^{\prime} \mathrm{R}_{\mathrm{r}}^{\prime}-\omega_{\mathrm{r}} \lambda_{\mathrm{dr}}^{\prime}+\rho \lambda_{\mathrm{qr}}^{\prime} \\
& \mathrm{v}_{\mathrm{dr}}^{\prime}=i_{\mathrm{dr}}^{\prime} R_{\mathrm{r}}^{\prime}+\omega_{\mathrm{r}} \lambda_{\mathrm{qr}}^{\prime}+\rho \lambda_{\mathrm{dr}}^{\prime}
\end{aligned}
$$

The flux linkages can be expressed as;

$$
\begin{aligned}
& \lambda_{\mathrm{qs}}=\mathrm{i}_{\mathrm{qs}} \mathrm{L}_{\mathrm{lqs}}+\lambda_{\mathrm{mq}} \\
& \lambda_{\mathrm{ds}}^{\prime}=\mathrm{i}_{\mathrm{ds}}^{\prime} \mathrm{L}_{\mathrm{lds}}^{\prime}+\lambda_{\mathrm{md}}^{\prime} \\
& \lambda_{\mathrm{qr}}^{\prime}=\mathrm{i}_{\mathrm{qr}}^{\prime} \mathrm{L}_{\mathrm{lqr}}^{\prime}+\lambda_{\mathrm{mq}} \\
& \lambda_{\mathrm{dr}}^{\prime}=i_{\mathrm{dr}}^{\prime} \mathrm{L}_{\mathrm{ldr}}^{\prime}+\lambda_{\mathrm{md}}^{\prime} \\
& \lambda_{\mathrm{mq}}=\mathrm{L}_{\mathrm{mq}}\left(i_{\mathrm{qs}}+i_{\mathrm{qr}}^{\prime}\right) \\
& \lambda_{\mathrm{md}}^{\prime}=\mathrm{L}_{\mathrm{md}}^{\prime}\left(\dot{i}_{\mathrm{ds}}^{\prime}+i_{\mathrm{dr}}^{\prime}\right)
\end{aligned}
$$

From Eqns. 2 the current can be expressed as;

$$
\begin{aligned}
& i_{\mathrm{qs}}=\left(\lambda_{\mathrm{qs}}-\lambda_{\mathrm{mq}}\right) / \mathrm{L}_{\mathrm{lqs}} \\
& i_{\mathrm{ds}}^{\prime}=\left(\lambda_{\mathrm{ds}}^{\prime}-\lambda_{\mathrm{md}}^{\prime}\right) / \mathrm{L}_{\mathrm{lds}}^{\prime} \\
& i_{\mathrm{qr}}^{\prime}=\left(\lambda_{\mathrm{qr}}^{\prime}-\lambda_{\mathrm{mq}}\right) / \mathrm{L}_{\mathrm{lr}}^{\prime} \\
& i_{\mathrm{dr}}^{\prime}=\left(\lambda_{\mathrm{dr}}^{\prime}-\lambda_{\mathrm{md}}^{\prime}\right) / \mathrm{L}_{\mathrm{lr}}^{\prime}
\end{aligned}
$$

From Eqns 2 and 3, The voltage equations can be rewritten in the following integral form;

$$
\begin{aligned}
& \lambda_{\mathrm{qs}}=\int\left(\mathrm{v}_{\mathrm{qs}}+\frac{\mathrm{R}_{\mathrm{qs}}}{\mathrm{L}_{\mathrm{lqs}}}\left(\lambda_{\mathrm{mq}}-\lambda_{\mathrm{qs}}\right)\right) \mathrm{dt} \\
& \lambda_{\mathrm{ds}}^{\prime}=\int\left(\mathrm{v}_{\mathrm{ds}}^{\prime}+\frac{\mathrm{R}_{\mathrm{ds}}^{\prime}}{\mathrm{L}_{\mathrm{lds}}^{\prime}}\left(\lambda_{\mathrm{md}}^{\prime}-\lambda_{\mathrm{ds}}^{\prime}\right)\right) \mathrm{dt} \\
& \lambda_{\mathrm{qr}}^{\prime}=\int\left(\mathrm{v}_{\mathrm{qr}}^{\prime}+\omega_{\mathrm{r}} \lambda_{\mathrm{dr}}^{\prime}+\frac{\mathrm{R}_{\mathrm{r}}^{\prime}}{\mathrm{L}_{\mathrm{lr}}^{\prime}}\left(\lambda_{\mathrm{rqq}}^{\prime}-\lambda_{\mathrm{qr}}^{\prime}\right)\right) \mathrm{dt} \\
& \lambda_{\mathrm{dr}}^{\prime}=\int\left(\mathrm{v}_{\mathrm{dr}}^{\prime}-\omega_{\mathrm{r}} \lambda_{\mathrm{qr}}^{\prime}+\frac{\mathrm{R}_{\mathrm{r}}^{\prime}}{\mathrm{L}_{\mathrm{lr}}^{\prime}}\left(\lambda_{\mathrm{rnd}}^{\prime}-\lambda_{\mathrm{dr}}^{\prime}\right)\right) \mathrm{dt}
\end{aligned}
$$

The developed electromagnetic torque is expressed as follows;

$$
\mathrm{T}_{\mathrm{em}}=\mathrm{P}\left(\lambda_{\mathrm{ds}}^{\prime} \mathrm{i}_{\mathrm{qs}}-\lambda_{\mathrm{qs}} i_{\mathrm{ds}}^{\prime}\right)
$$

The mechanical equation can be written in the following integeral form;

$$
\omega_{\mathrm{r}}=\frac{1}{\mathrm{~J}} \int\left(\mathrm{T}_{\mathrm{em}}-\mathrm{T}_{\text {load }}-\mathrm{T}_{\mathrm{damp}}\right) \mathrm{dt}
$$


The operation alternates between two different modes. In Mode 1 switch $S_{1}$ is turned-on while switch $S_{2}$ is turned-off. During this mode, the motor is working as a split-phase. The capacitor charge as well as its terminal voltage remains constant until $S_{2}$ is turned-on. The voltage applied on the auxilary winding is the supply voltage i.e.

$\mathrm{v}_{\mathrm{ds}}=\mathrm{v}_{\mathrm{s}}$

In Mode 2 switch $S_{1}$ is turned-off while switch $S_{2}$ is turned-on. During this mode the motor is working as a capacitor-run motor. The voltage applied on the auxilary winding is the difference between the supply and capacitor voltages i.e.

$\mathrm{v}_{\mathrm{ds}}=\mathrm{v}_{\mathrm{s}}-\mathrm{v}_{\mathrm{c}}$

and the capacitor voltage is given by;

$\mathrm{v}_{\mathrm{c}}=\frac{1}{\mathrm{C}} \int \mathrm{i}_{\mathrm{ds}} \mathrm{dt}$

The above mathematical model is simulated on the SIMULINK within MATLAB software evironment. A schametic of the main simulation program is shown in Fig. 4 . It consists of four subprograms which are shown by four blocks within the main program. These subprogranas are Capacitor, $Q$-axis, $D$ axis and Torque. Within the Capacitor subprogram the switching process for the controlled capacitor is carried-out. The output of this block is the q-axis voltage, the d-axis voltage and the capacitor voltage at the instant of calling. Both the $Q$-axis and $D$-axis blocks are in charge of the numerical solution of the integral equations of both axes. Within the Torque block the electromagnetic torque is obtained and the mechanical equation is integrated. The simulation results are displayed on line with the scope block and exported to the MATLAB work space for further study.

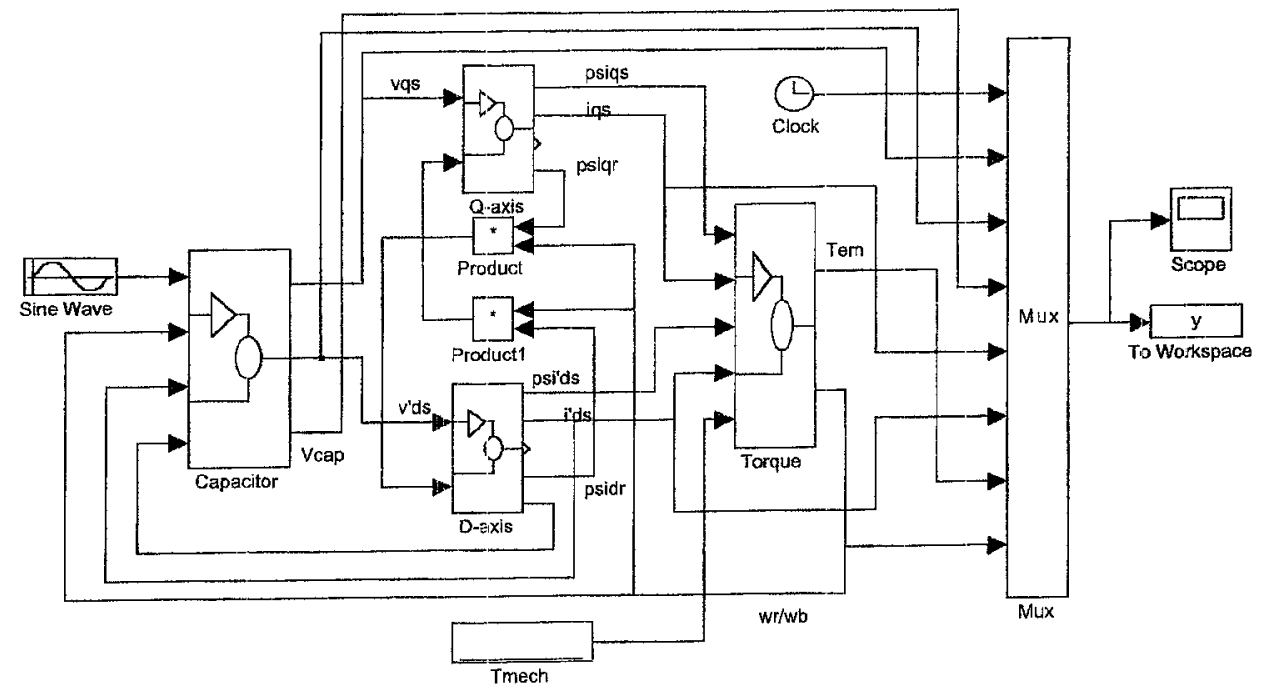

Fig. 4 The SIMULINK schametic diagram for simulation program. 


\section{SIMULATION AND EXFERIMENTAL RESULTS}

In this section a relation between the duty ratio and effective capacitance has been obtained. The voltage and current wavefons of the auxiliary circuit as well as that of the control circuit are given. A study of the motor starting characteristics has been carried-out which includes starting with different capacitors, starting with a switched-capacitor at different duty ratios and speed response for the closed-loop controlled capacitor.

\section{4-1. The Relation Between Duty Ratio And Effective Capacitance}

An RLC circuit connected as shown Fig. 5-a has been analyzed to study the effect of the switching process on the effective capacitance. A constant capacitance of $20 \mu \mathrm{F}$ is connected in series with switch $S_{2}$ to a parallel switch $S_{1}$ which are alternately switched with a high frequency compared to that of the ac supply $V_{s}$. The current $i_{s}$ is obtained and from which the effective capacitance was calculated for different values of the ratio $k$. The calculation has been repeated many times for different values of $R$ and $L$ and it was found that the effective capacitance is independent of these parameters and it depends solely on the ratio $k$. From this analysis it was found that the effective capacitance varies with the ratio $k$ as shown in Fig. 5-b.

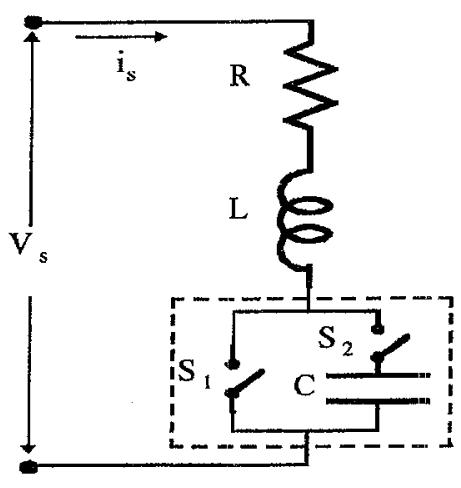

(a)

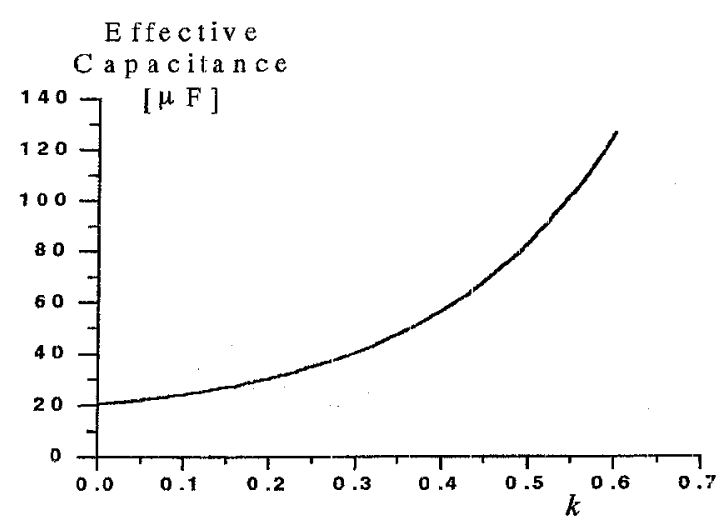

(b)

Fig. 5. The relation between the effective capacitance and the duty ratio $k$.

\section{4-2. Optimum Capacitance For Starting And Running The Motor}

To find-out the effect of varying the auxiliary capacitance on the motor starting performance, the starting torque has been obtained analytically for different capacitor values up to $80 \mu \mathrm{F}$, Fig. 6 . From this figure it is clear that the starting torque can be increased by increasing the auxiliary capacitance up to a certain value after which the starting torque begins to decrease. For the motor under investigation the maximum starting torque can be obtained at about $70 \mu \mathrm{F}$.

The motor running performance has been studied for different auxiliary winding capacitances by varying the capacitor value physically. The motor was run under load such that its speed is kept constant at its rated full-load speed 
whatever the value of the capacitor. The capacitance was changed over the range from 5 to $40 \mu \mathrm{F}$. The moter-efficiency, input current and input power factor has been obtained experimentally and theoretically and shown in Figs. 7,8,9. The motor efficiency is shown in Fig. 7 in which it is clear that the efficiency increased by increasing the capacitor value up to a certain level after which it begins to decrease. An optimum value for the auxiliary capacitor which maximizes the motor efficiency can be obtajned from this figure. In Fig. 8 The motor input current is shown to be decreased by incraasing the auxiliary capacitor up to a certain level after which it begins to increase by increasing the capacitor. The optimum value for the auxiliary capacitor which minimizes the motor input current can be obtained from this figure. In Fig.9 the motor input power factor is shown to be increased by increasing the capacitance up to unity and stays almost flat.

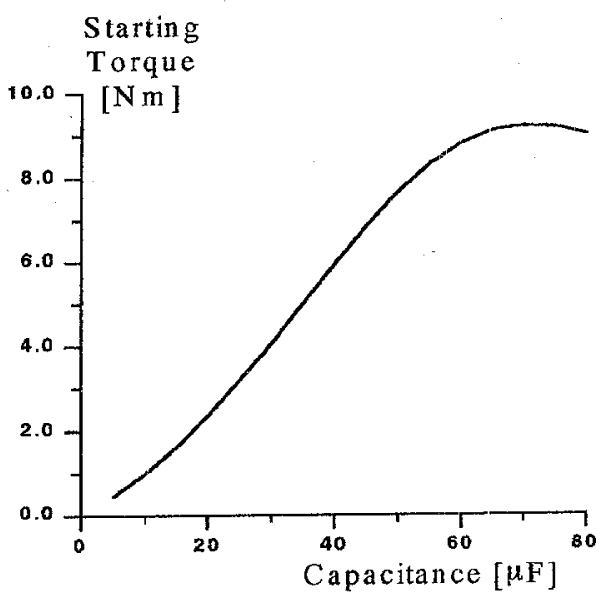

Fig. 6 The motor starting torque for different capacitor values (simulation)

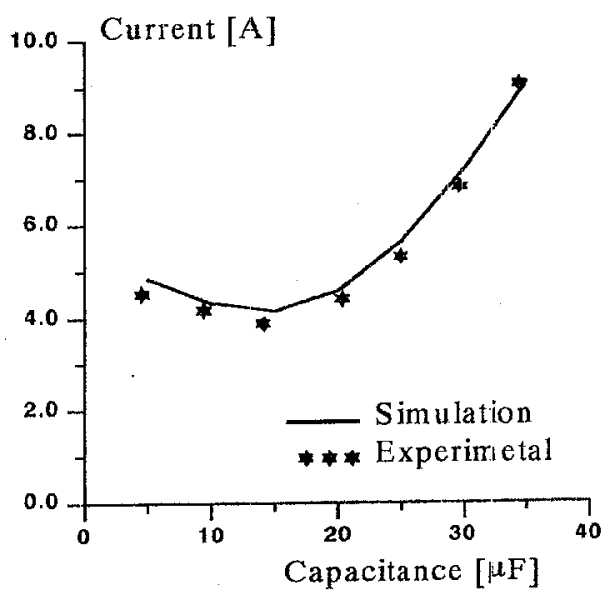

Fig. 8 The motor current at full load with different capacitor values

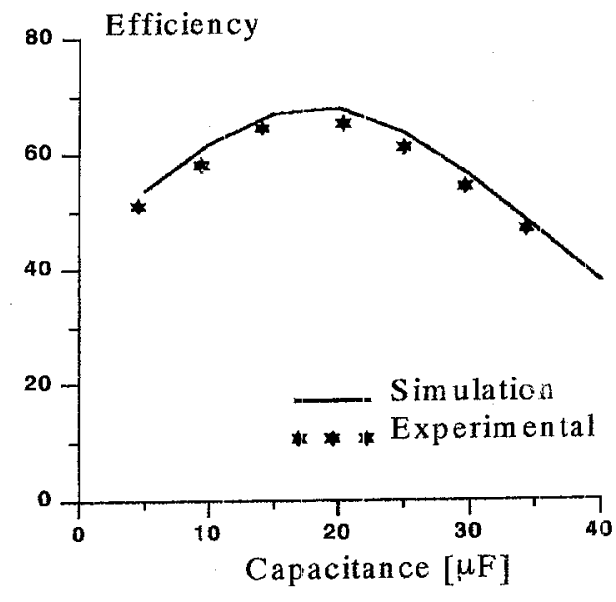

Fig. 7 The motor efficiency at full -load with different capacitor values

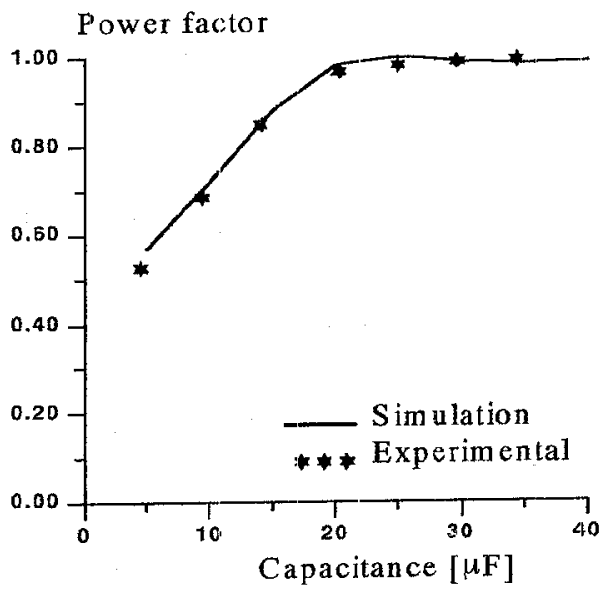

Fig. 9 The input power factor at full load with differentcapacitor values 
From these results it can be concluded that the motor running performance is greatly affected by the value of the auxiliary capacitor. There is allways an optimum running capacitance which maximizes the efficiency and power factor and minimizes the motor input current. For the motor under investigation, the optimum running capacitance is slightly less than $20 \mu \mathrm{F}$. Since the value of $20 \mu \mathrm{F}$ is the value recommended by the manufacturer for running the motor, it has been chosen as the constant value to be controlled.

$$
\text { : }:=
$$

To study the way in which the capacitance should be varied, the torque-speed characteristic have been obtained for different capacitor values. From these characteristic the capacitance which maximizes the developed torque at each speed is selected as an optimum value for that speed. The optimum capacitance curve over the entire speed range is obtained and plotted as shown in Fig. 10. It is observed that the optimum capacitance is maximum at starting and gets lower by increasing the motor speed, however its rate of change depends on the speed. It is also observed that the optimum capacitance at zero speed which obtained from this curve agree with that one obtained from Fig.6.

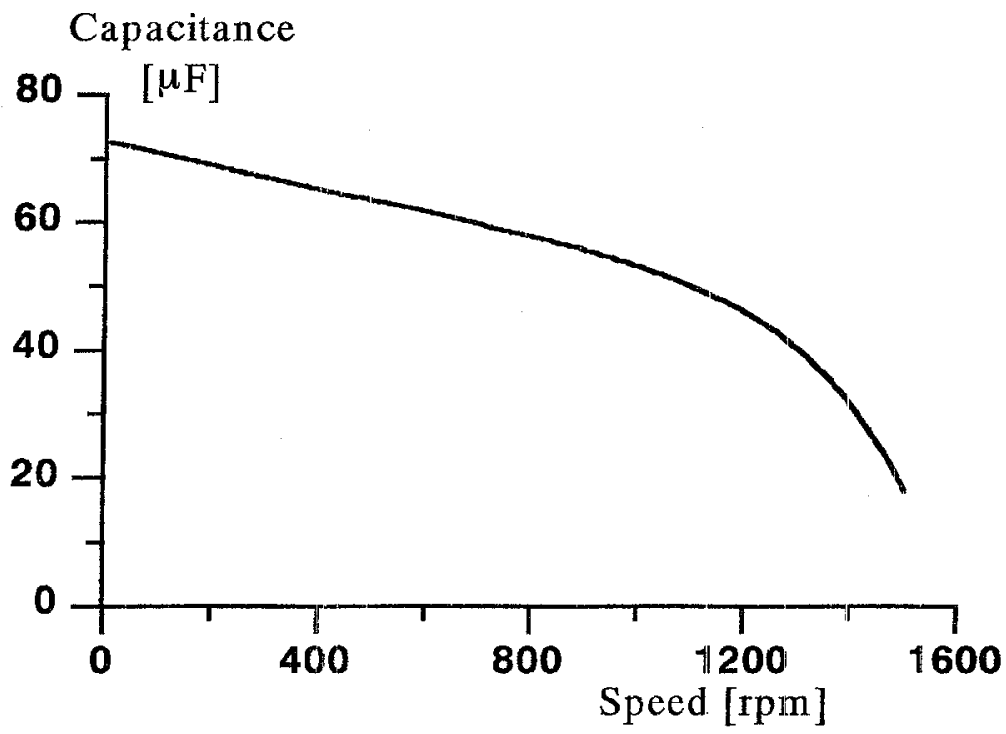

Fig. 10 The optimum capacitance over the entire speed range (simulation).

From these results it can be concluded that the optimum starting and running performance of the single-phase induction motor requires that the auxiliary capacitance should be continuously varied with the motor speed. It is not always practical to vary the auxiliary capacitance physically to obtain the optimum performance at different speeds. However, the proposed controlledcapacitor scheme seems to be a suitable means to obtain such varying capacitance for the motor. 


\section{4-3. Voltage And Current Waveforms'}

The system has been tested with proposed switched-capacitor scheme in an open loop. The control circuit is set to work with a constant value of $V_{\text {ref }}$ to investigate the switching process on the current and voltage waveforms. The simulation and experimental waveforms of the triangular high frequency carrier, reference voltage $V_{\text {ref }}$ and gate pulses are shown in Fig. 11.

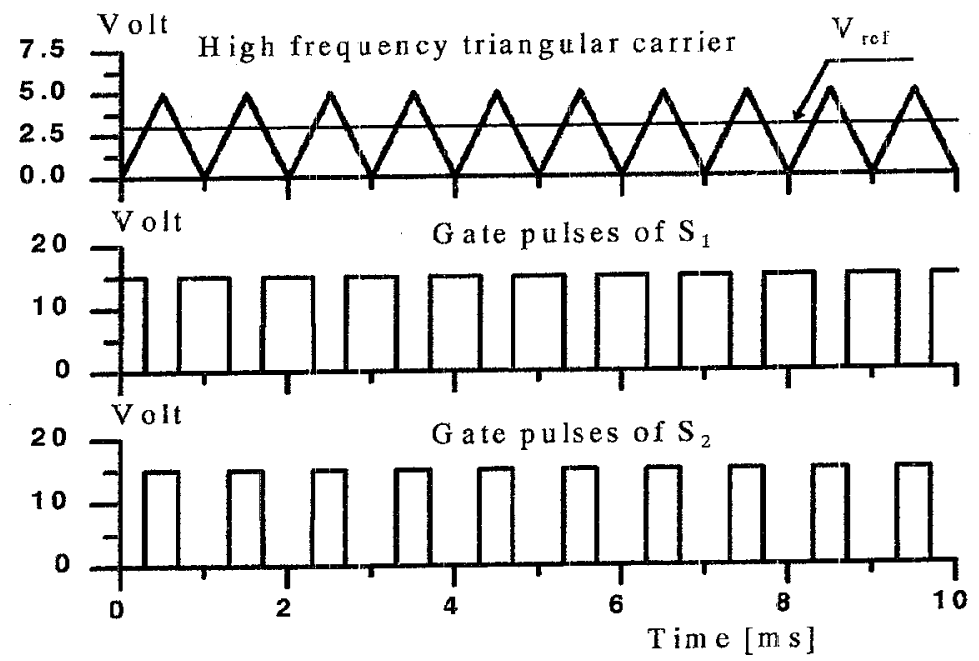

(a) Simulation waveforms

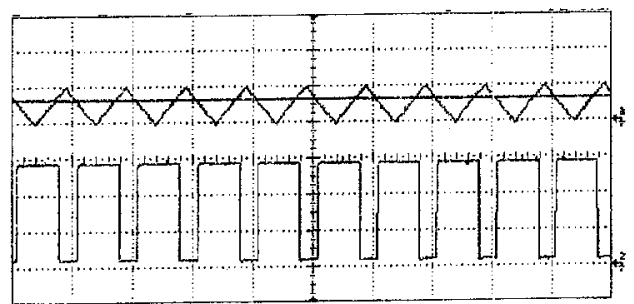

Gate pulses of $S_{1}$

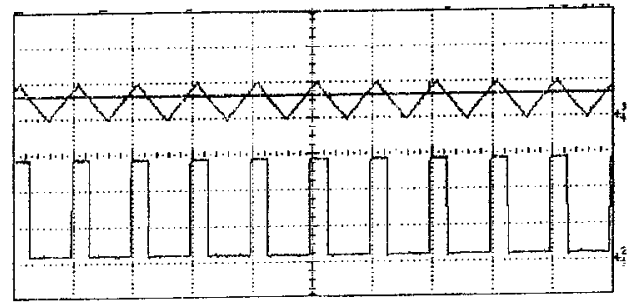

Gate pulses of $\mathrm{S}_{2}$

(b) Experimental waveforms.

Fig. 11 Triangular carrier, $V_{\text {ref }}$ and gate pulses for $S_{1}$ and $S_{2}$ at $k=0.65$

The auxiliary winding vollage and current are shown in Fig. 12. The capacitor voltage and current waveforms are shown in Fig. 13. It is clear from Figs. 12 and 13 that the switching process was successfully implemented and there is a good agreement between experimental and simulation results. The auxiliary winding current is approximately sinusoidal which is considered one of the merits of the proposed scheme. The capacitor current is a train of pulses within an envelop of a sine wave which verifies that the capacitor is inserted repeatedly in series with the auxiliary winding. It should be noted that the time axis of the simulation results does not start from zero since these results are the steady-state part of the simulation results. 


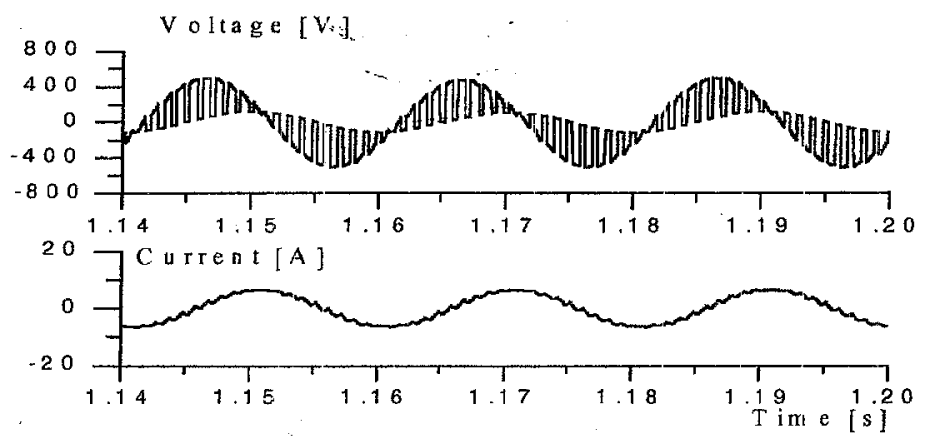

(12-a) Simulation waveforms.

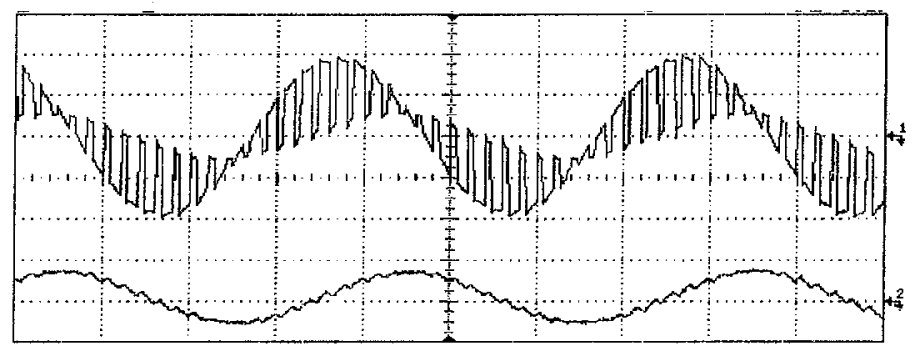

(12-b) Experimental waveforms.

Top: Voltage $400 \mathrm{~V} / \mathrm{div}$, Bottom: Current $10 \mathrm{~A} / \mathrm{div}$

Fig. 12. Auxilary winding voltage and current at $k=0.3$

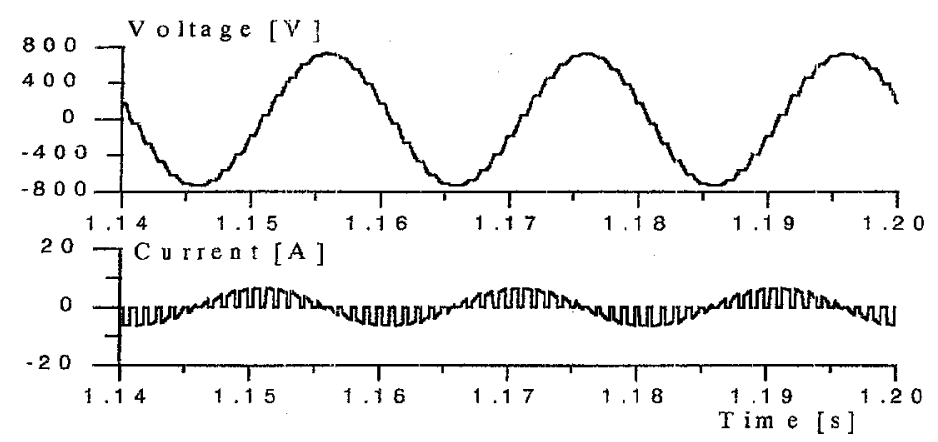

(13-a) Simulation waveforms.

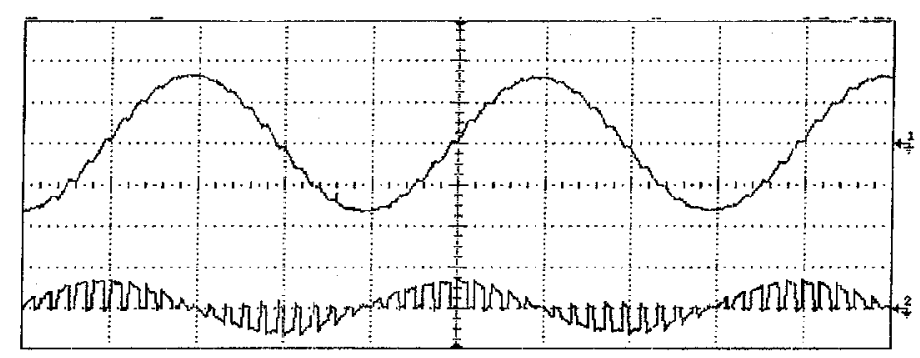

(13-b) Experimentl waveforms.

Top: Voltage $400 \mathrm{~V} / \mathrm{div}$, Bottom: Current $10 \mathrm{~A} / \mathrm{div}$

Fig. 13 Capacitor voltage and current at $k=0.3$ 
The simulation and experimental waveforms of the voltage across the parallel switch $V_{a b}$ and the auxiliary winding current are shown in Fig. 14. The voltage $V_{a b}$ is the voltage drop across the auxiliary capacitance as it is seen by the auxiliary winding. It is PWM pulses superimposed on a sine wave with an effective value depends on the duty ratio $k$. The effective value of $V_{a b}$ is low for high duty ratio $\mathrm{k}$ and vice versa.
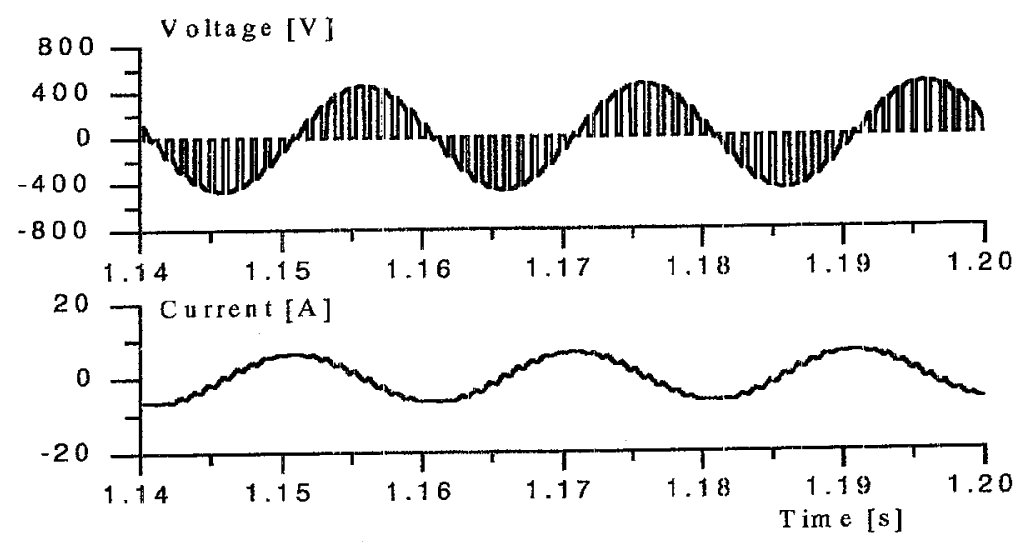

(14-a) Simulation waveforms.

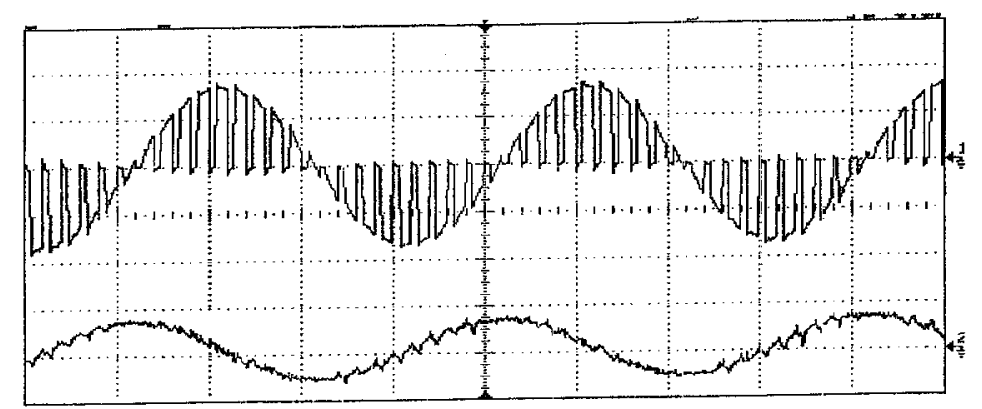

(14-b) Experimentl waveforms.

Top: Voltage $400 \mathrm{~V} / \mathrm{div}$, Bottom: Current $10 \mathrm{~A} / \mathrm{div}$

Fig. 14 The voltage across the parallel switch $S 1 V_{a b}$ and the auxiliary winding current at $k=0.3$

\section{4-4. No-load Starting Characteristics}

\section{4-4-1. Starting characteristics for different capacitors at no-load}

A study has been carried-out to find out the starting capacitance which minimizes the starting time. The starting response has been calculated many times with different capacitor values and the time required for the motor to reach its steady-state speed is considered as the starting time. The results of this analysis are plotted in Fig. 15. From this figure it can be concluded that a capacitance of about $60 \mu \mathrm{F}$ is considered an optimurn starting value to minimize the starting time for the motor under investigation. This result is approximately near that result obtained frona Figs. 6 and 10. 


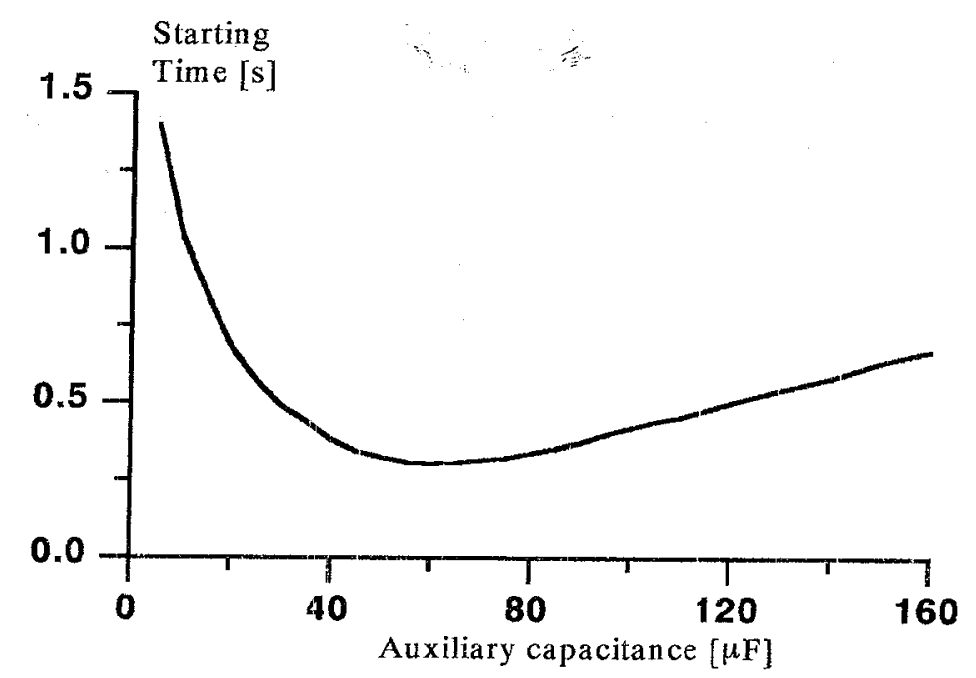

Fig. 15 The relation between the starting time and the auxiliary capacitance (Simulation).

The speed response has been studied for open loop operation with different capacitor values. Figures 16,17 show the speed response for an auxiliary capacitor of $20 \mu \mathrm{F}$ and $40 \mu \mathrm{F}$ respectively. It is observed that the starting time decreases with the increase of the auxiliary capacitance which verifies the conclusion obtained from Fig. 15.

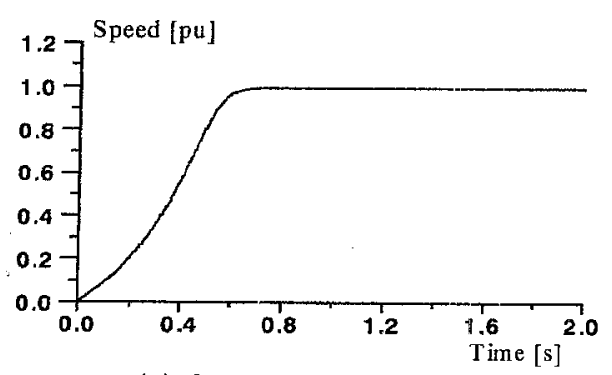

(a) Simulation

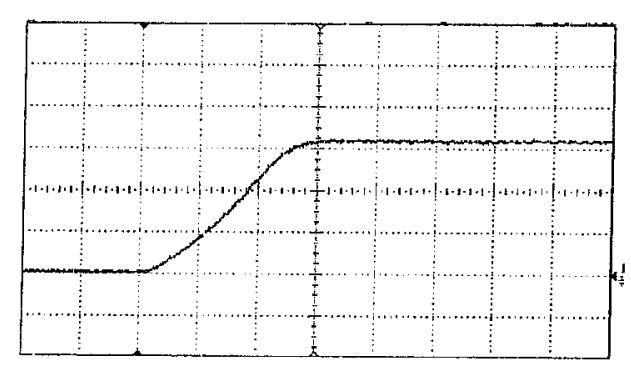

(b) Experimental (time $0.2 \mathrm{~s} / \mathrm{div}$ )

Fig. 16 Speed response for $20 \mu \mathrm{F}$.

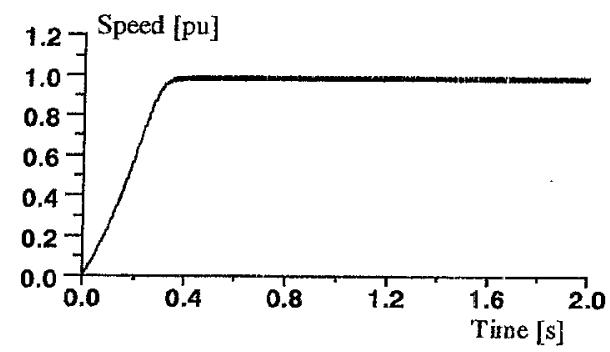

(a) Simulation

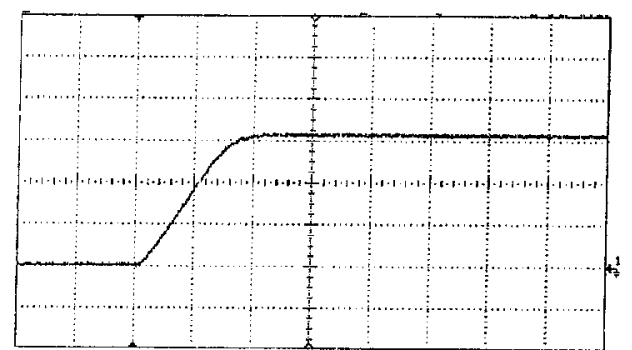

(b) Experimental (time $0.2 \mathrm{~s} / \mathrm{div}$ )

Fig. 17 Speed response for $40 \mu \mathrm{F}$. 


\section{4-4-2. Starting characteristics with switched capacitor}

The system is then investigated with the switched capacitor in an open loop. The starting time is obtained at different values of $V_{\text {ref }}$ to vary the duty ratio $k$. The relation between the duty ratio and the starting time is shown in Fig. 18. It is observed that by increasing the duty ratio $k$ the starting time decreases which indicates that the effective capacitance increases with that ratio. There is a certain duty ratio at which the starting time is minimum. This value corresponds to the optimum effective capacitance. Any attempt to increase the duty ratio after that would result an increase in the starting time. This is due to introducing an effective capacitance greater than the optimum starting value. Comparing Figs. 18 and 15 , it is observed that varying the duty ratio has an effect similar to the physical variation of the auxiliary capacitance.

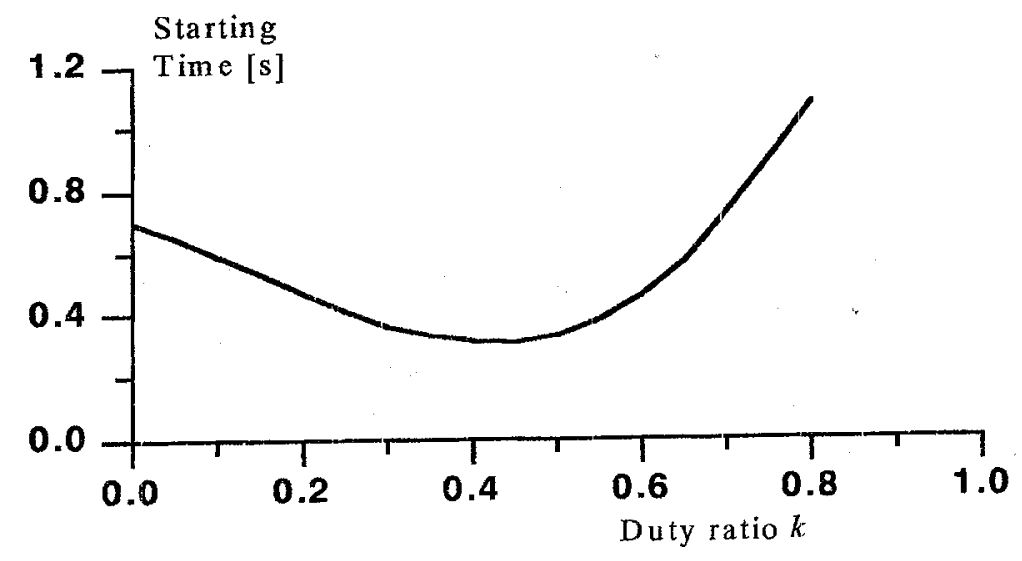

Fig. 18 The relation between the starting time and duty ratio $k$.

The speed responses with the switched capacitor with different duty ratios are shown in Figs. 19, 20. Figure 19 is obtained with a duty ratio of 0.15 which corresponds to a low effective capacitance (Fig.5), while Fig. 20 is obtained with a duty ratio of 0.4 which corresponds to a higher effective capacitance. It is clear that the speed response gets faster by increasing the duty ratio, however there is an upper limit for this ratio after which the response is slower (as shown in Fig.18).

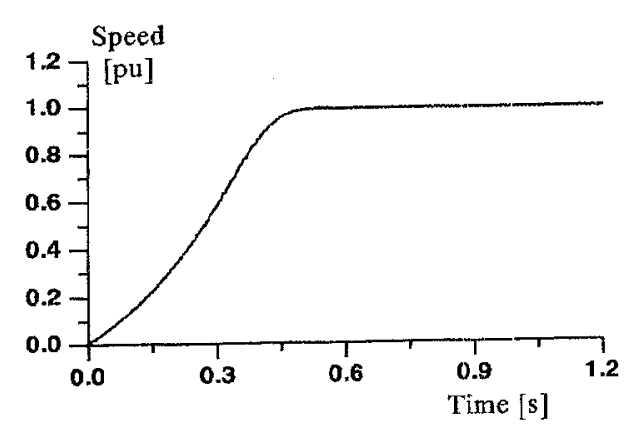

(a) Simulation

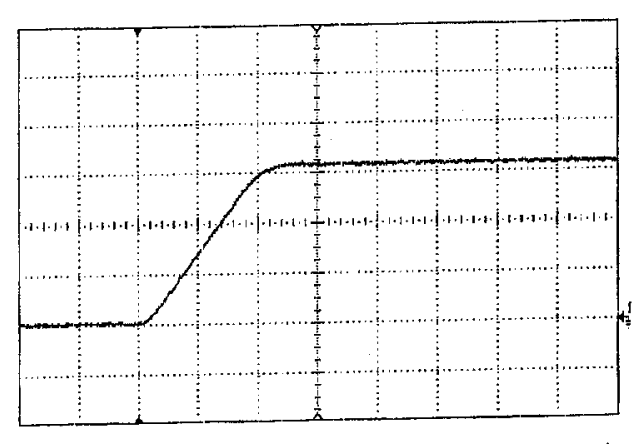

(b) Experimental (time $0.2 \mathrm{~s} / \mathrm{div}$ )

Fig. 19. Speed response for switched capacitor at $k=0.15$ 


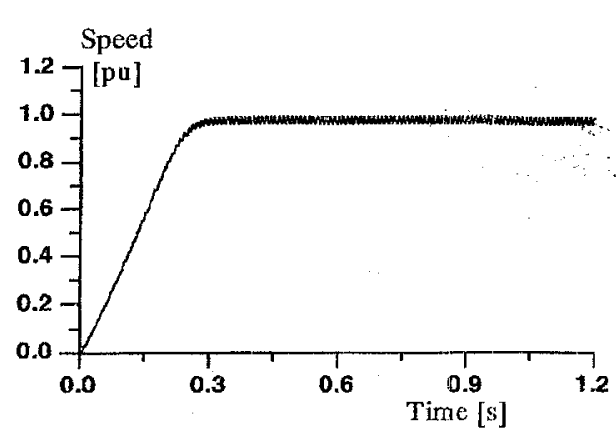

(a) Simulation

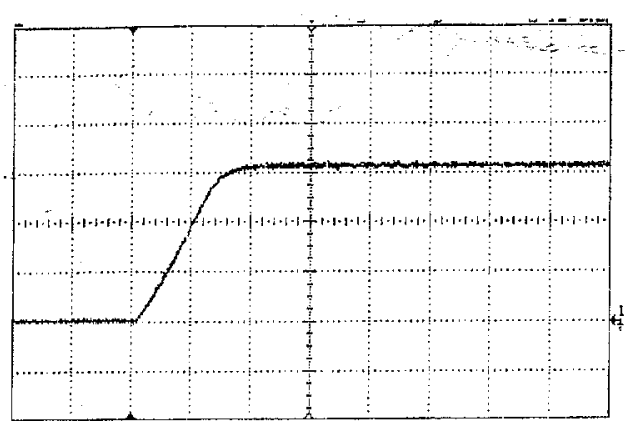

(b) Experimental (time $0.2 \mathrm{~s} / \mathrm{div}$ )

Fig. 20. Speed response for switched capacitor at $k=0.4$

\section{4-4-3. Starting response for closed-loop controlled capacitor}

The system has been investigated with the closed-loop controlled capacitor. At starting the motor speed is too low, accordingly a high value of $V_{\text {ref }}$ is obtained which results-in gate pulses with high duty ratio for driving $S_{1}$. This case corresponds to a high capacitance value (Fig. 5). At high speed the value of $V_{\text {ref }}$ is low which contributes narrow pulses with low duty ratio for driving $S_{1}$. The second case corresponds to low capacitance value (Fig 5).

Fig. 21 shows the simulation and experimental results of the speed response for the controlled capacitor. The simulation speed response for both controlled and constant capacitor value of $20 \mu \mathrm{F}$ is shown in Fig. 21-a. It is clear that there is a substantial improvement of the response due to the controlled capacitor which is a direct result for the improvement of the motor starting torque. The experimental speed response for a controlled capacitor of $20 \mu \mathrm{F}$ is shown in Fig. 21-b. There is also a good agreement between simulation and experimental results.

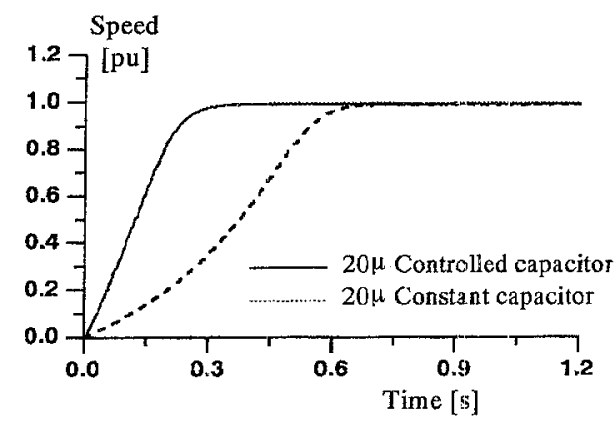

(a) Simulation

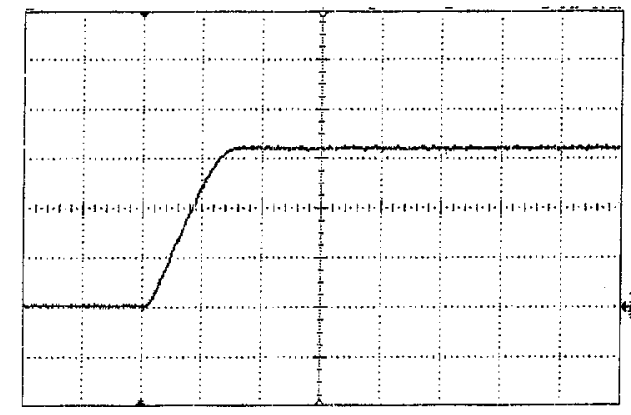

(b) Experimental (time $0.2 \mathrm{~s} / \mathrm{div}$ )

Fig. 21 Speed response with a controlled capacitor. 


\section{CONCLUSIONS}

A statically controlled capacitor scheme has been introduced in order to improve starting and running performance of the single-phase induction motor. The scheme is based on two fast switching electronic devices (IGBT) driven by a simple PWM control circuit. A d-q model for the motor operating under the proposed control scheme has been developed and numerically solved. The present study shows that the auxiliary capacitance greatly affect the motor performance in both starting and running conditions. The high performance operation is possible by inserting a certain high capacitance in series with the auxiliary winding at starting and varying it continuously down to another certain optimum value at running. The optimum operating conditions for minimizing both the starting time and the motor input current and for maximizing the developed torque, efficiency and power factor have been obtained. A relation between the duty ratio of the control circuit and the effective capacitance has been obtained. The results shows a substantial improvement in the motor speed response by introducing the proposed control scheme to the capacitor circuit which is a direct result for the improvement of the motor starting torque. A laboratory system has been built and tested to verify the proposed control scheme. The good agreement between experimental and simulation results verifies the accuracy of the mathematical model and the simulation.

\section{REFERENCES}

[1] M. A. Abdel-Halim, "Control of Single-Phase Induction Motor Using Forced-Commutated Electronic Switches", Electric Power and Mlachines, Vol. 25, 1997, PP 1119-1133

[2] T. A. Lettenmaier, D. W. Novotny and T. A. Lipo, "Single-Phase Induction Motor with an Electronically Controlled Capacitor", IEEE Trans. on Industary Applications, Vol. 27, No 1 January/February 1991

[3] J. Faiz and A. Servatian, "Optimization of an Electronically Controlled Capacitor for a Single-Phase Induction Motor", Electric Power and Machines, Vol. 26, 1998, PP 1067-1079

[4] E. Muljadi, T. Liu and T. A. Lipo, "Adjustable ac Capacitor for a SinglePhase- Induction Motor", IEEE Trans. on Industary Applications, Vol. 29, No 3 May/June 1993

[5] Tian-Hua Liu, "A Maximum Torque Control with A Controlled Capacitor for a Single-Phase Induction Motor", IEEE Trans. on Industary Applications, Vol. 42, No 1 February 1995

[6] A. E. Lashine, S. M. R. Tahoun and F. A. Salafan, "A. High Performance Single-Phase Reluctance Motor with Statically Controlled Capacitor", Alexandria Engineering Journal, Vol. 37, No 4, B83-B95, July 1998 


\section{APPENDIX}

\section{A-1. Motor Data;}

$220 \mathrm{~V}, 0.5 \mathrm{kw}, 50 \mathrm{~Hz}, 4$-pole, 4.2. A capacitor-start capacitor-run single-phase induction with a starting capacitor of $20 \mu \mathrm{F}$ and a nun capacitor of $40 \mu \mathrm{F}$

\section{A-2. Motor Parameters}

Main winding resistance

$0.0555 \mathrm{pu}$

Main winding leakage reactance

$0.0610 \mathrm{pu}$

Auxilary winding resistance

$0.1910 \mathrm{pu}$

Auxilary winding leakage reactance

$0.2007 \mathrm{pu}$

Rotor resistance referred to the main winding

$0.1031 \mathrm{pu}$

Rotor leakage reactance referred to the main winding

$0.0610 \mathrm{pu}$

Magnetizing reactanceof the main winding

$0.6549 \mathrm{pu}$

Main to auxilary turns ratio

$1 / 1.68$

Rotor inertia

$0.0533 \mathrm{~kg} . \mathrm{m}^{2}$

\section{A-3. List of Symbols}

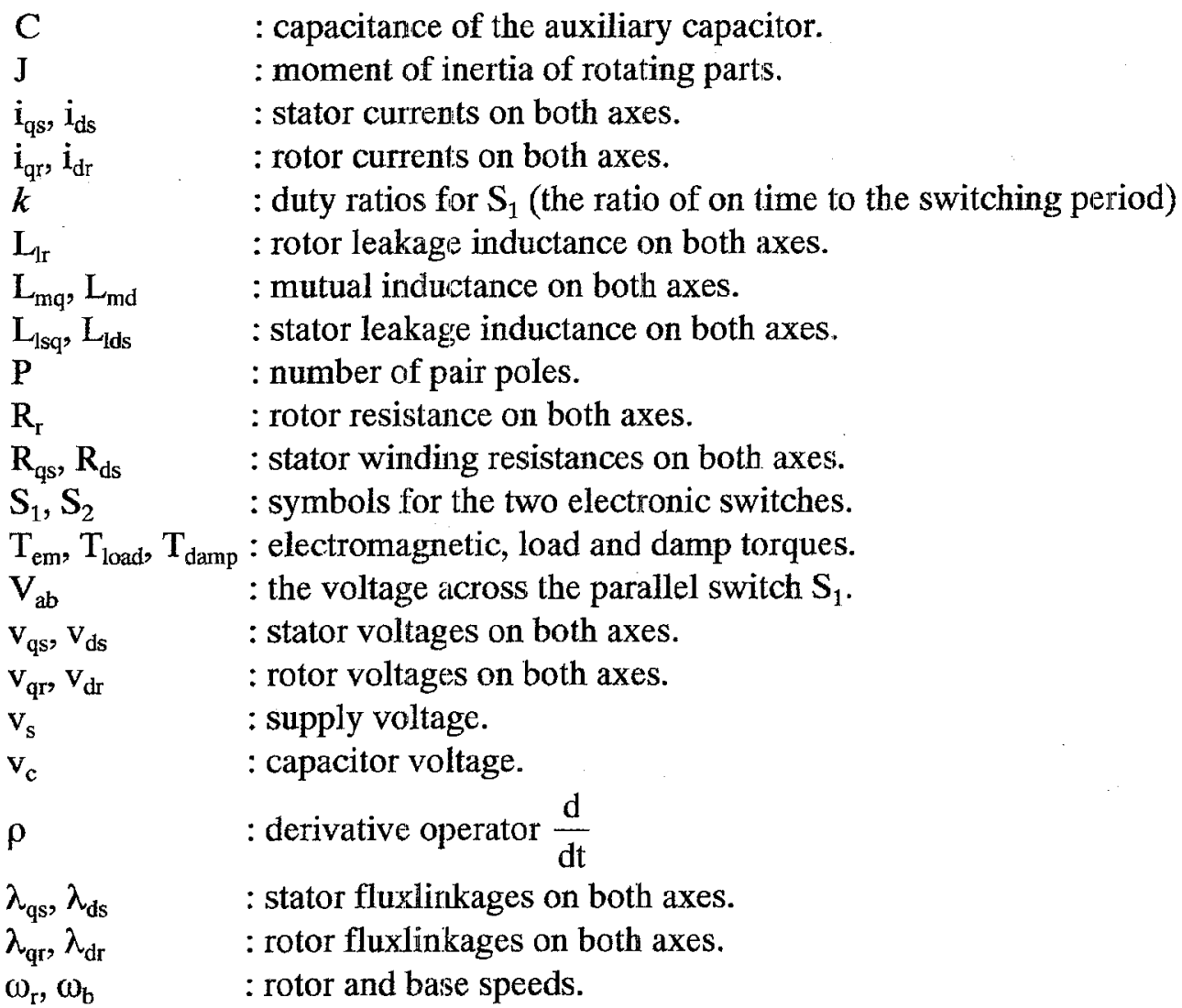

Note: The prime on any symbol means that its value is referred to the stator main winding. 


\title{
تحدين خصائه المصرك التأثيرى أحادى الوجه باستخدام المكثف المحكوم إلكترونيا
}

\author{
د./ محمود مصطفى خاملر \\ قسم الهندسة الكهربية - كلية الهندسة بشبين الكوم - جامعة المنوفية همثية
}

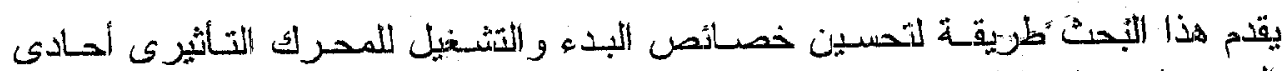

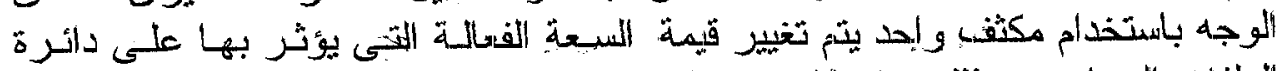

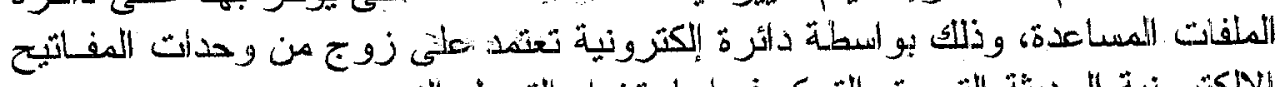

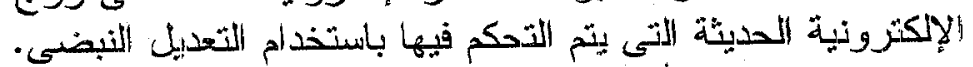

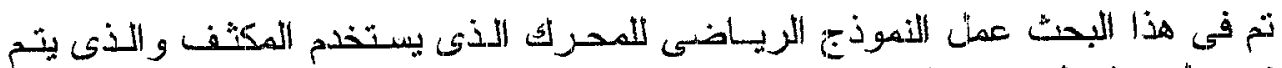

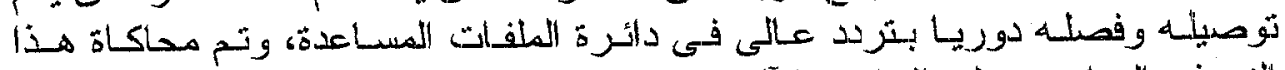

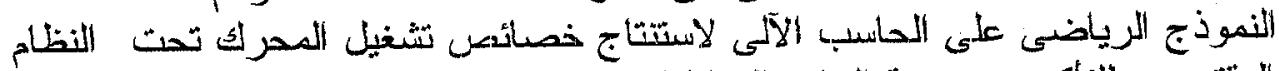

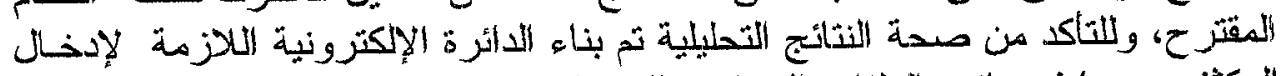

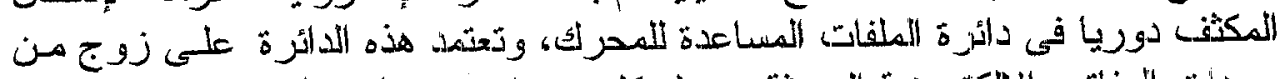

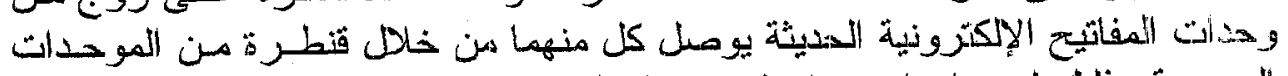

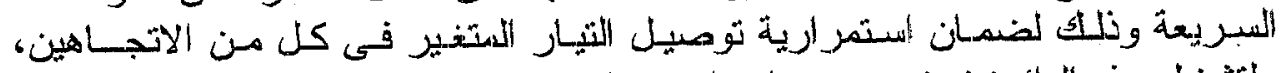

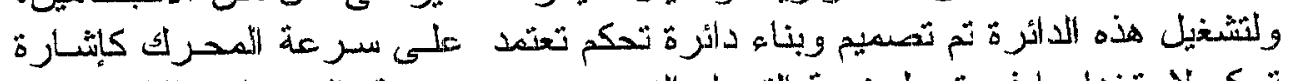

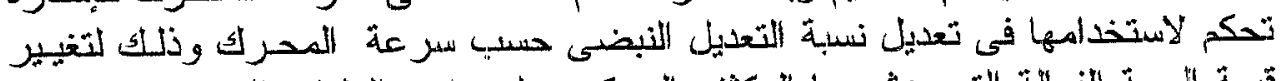

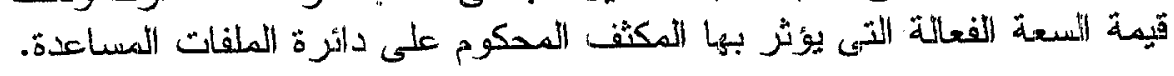

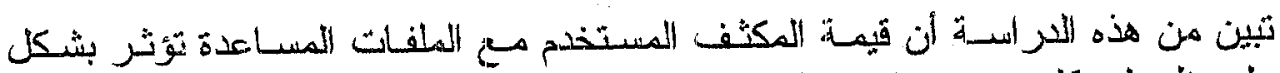

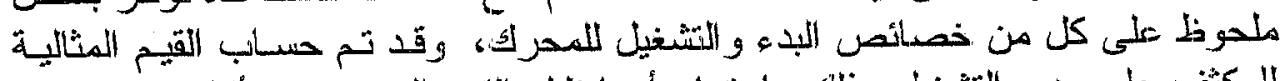

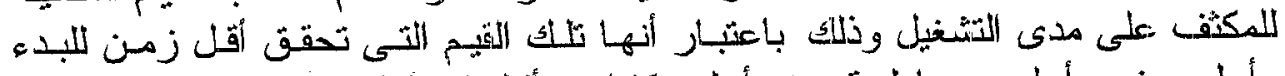

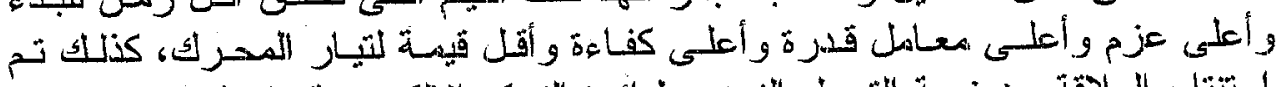

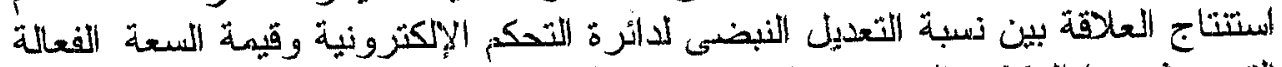

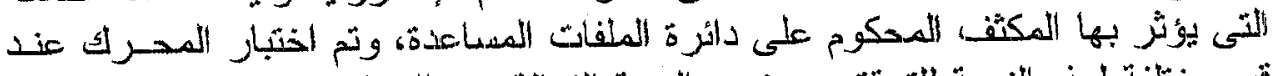

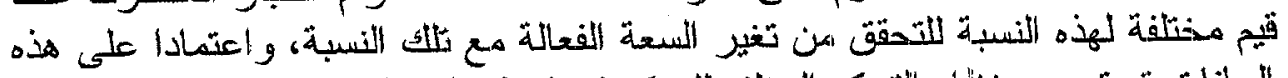

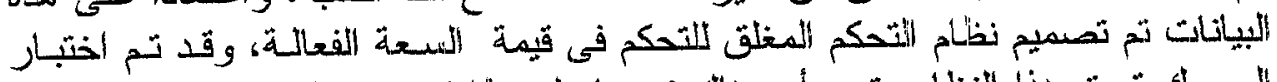

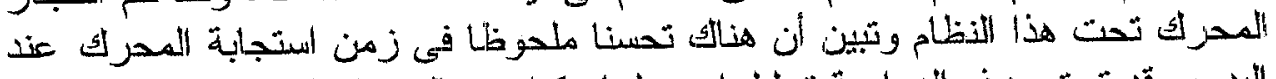

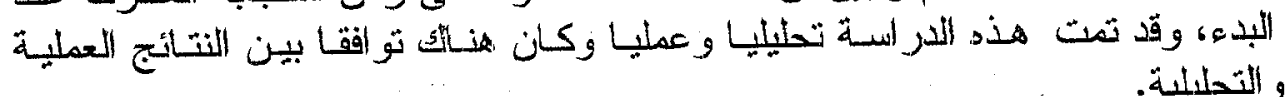

